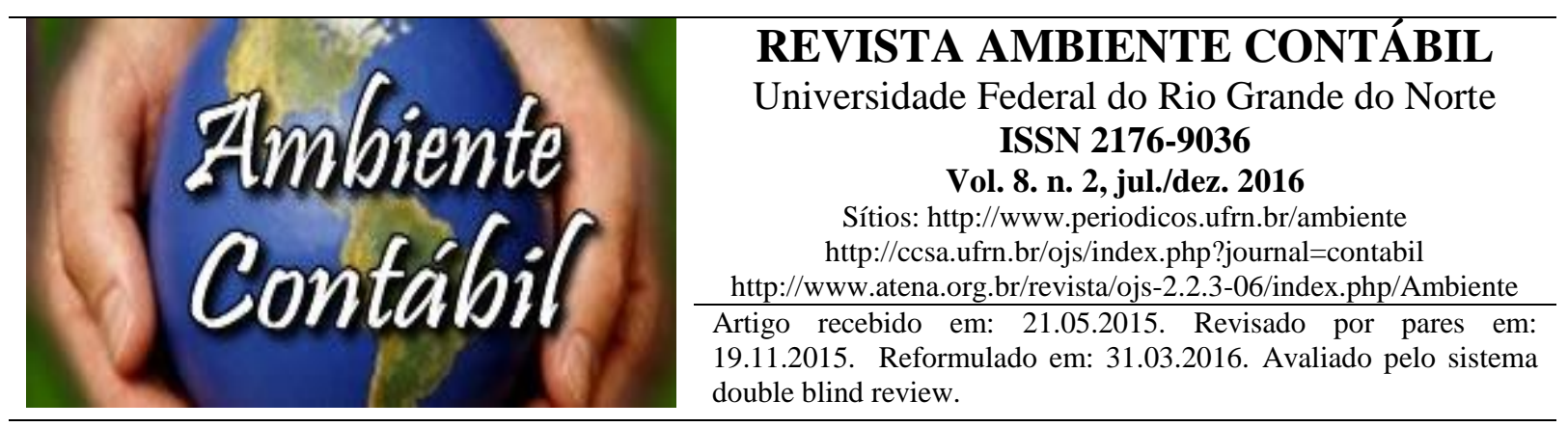

\title{
EMPRESAS QUE DISTRIBUEM DIVIDENDOS E ADOTAM GOVERNANÇA CORPORATIVA TEM RETORNOS ANORMAIS EM SUAS AÇÕES?
}

\section{NOW THAT DISTRIBUTE DIVIDENDS AND ADOPT CORPORATE GOVERNANCE HAS ABNORMAL RETURNS IN THEIR ACTIONS?}

\section{AHORA QUE DISTRIBUIR DIVIDENDOS Y ADOPTAR GOBIERNO CORPORATIVO TIENE RENDIMIENTOS ANORMALES EN SUS ACCIONES?}

\section{Autores}

\section{Silvio Freitas da Silva}

Mestre em Ciências Contábeis da Universidade Federal do Espírito Santo - UFES Professor da Universidade Estadual do Mato Grosso do Sul - UEMS - Endereço: Cidade Universitária de Dourados - Caixa postal 351 - CEP: 79804-970 - Dourados - MS Brasil - Telefone: (67) 3902-2360 / Fax: (67) 3902-2364. Telefone: (27) 99900-7841

E-mail: silviofreitas_17@hotmail.com

\section{Bruno Fraislebem Formentini}

Mestrando em Ciências Contábeis da Universidade Federal do Espírito Santo - UFES -

Coordenador da Gerência de Contabilidade do Banco do Estado do Espírito Santo BANESTES S/A - Endereço: Av. Fernando Ferrari, 314, Centro de Ciências Jurídicas e Econômicas - Campus Goiabeiras; CEP: 29.075-910; Vitória - ES - Brasil Telefone: 2799900-7841

E-mail: brunoformentini@banestes.com.br

\section{Donizete Reina}

Mestre em Contabilidade pela Universidade Federal de Santa Catarina - Professor Assistente da Universidade Federal do Espírito Santo - Endereço: Av. Fernando Ferrari, no 514 , Goiabeiras. Vitória - ES - Brasil. Telefone: (27) 4009-2602

E-mail: dreina2@hotmail.com

\section{Alfredo Sarlo Neto}

Doutor em Ciências Contábeis pela Universidade de São Paulo - Professor Adjunto da Universidade Federal do Espírito - Endereço: Av. Fernando Ferrari, n ${ }^{\circ}$ 514, Goiabeiras.

Vitória - ES - Brasil. Telefone: (27) 4009-4444

E-mail: supersarloneto@gmail.com 


\title{
RESUMO
}

Ball e Brown (1968) relatam que lucro líquido é uma informação contábil relevante para os investidores como critério na decisão de investir na empresa, deste modo, as informações produzidas pelas demonstrações contábeis podem explicar o retorno das ações. Assim, estudo tem por objetivo analisar a influência das políticas de dividendos e o nível de governança nos retornos anormais das ações das empresas listadas na BM\&FBovespa no período de 2010 a 2013. Esta pesquisa é quantitativa, com análise de 255 empresas, sobre os impactos do anúncio do pagamento dos dividendos no retorno anormal da ação por meio de um modelo de regressão múltipla linear. Os resultados apontaram que os retornos anormais sofreram grandes variações e não há uma relação direta entre dividend yields e retorno anormal das ações, contrapondo o estudo de Novis Neto e Saito (2003). No entanto, corroboraram com Nagem e Amaral (2012), quanto aos retornos anormais sofrerem grandes variações sem uma relação direta entre dividend yields e retorno anormal das ações; a variável governança corporativa apresentou resultado insignificante, com evidências de que a mesma não influência no retorno anormal das ações; e empresas listadas em alguns níveis diferenciados de governança corporativa do Ibovespa não tem significância no poder de informatividade do retorno anormal.

Palavras-chave: Distribuição de Dividendos. Retorno Anormal das Ações. Informatividade. Governança Corporativa.

\begin{abstract}
Ball and Brown (1968) reported that net income is relevant for investors in order to decide whether or not to invest in the company, thus the information produced by the financial statements may explain the stock returns. This study aims to analyze the influence of dividend policy and the governance level in abnormal stock returns of companies listed on the BM \& FBOVESPA. This research is quantitative, with analysis of 255 companies, about the dividend payment announcement impacts on the abnormal return of shares by means of regression model. The results showed that the abnormal returns had wide variations and there is a direct relationship between dividend yields and abnormal stock returns, contrasting the study of Novis Neto and Saito (2003). However, they corroborated Nagem and Amaral (2012), when it comes to abnormal returns, they had large variations without a direct relationship between dividend yields and abnormal stock returns; the corporate governance variable showed insignificant results, with evidence that it does not influence the abnormal stock returns; and companies listed in some different Ibovespa levels of corporate governance had no significance in the power of informativeness of abnormal return.
\end{abstract}

Keywords: Dividend Distribution. Abnormal Return of the Shares. Informativeness. Corporate Governance.

\section{RESUMEN}

Ball y Brown (1968) reportaron que el ingreso neto es una información contable a los inversores como criterio en la decisión de invertir en la empresa, por lo tanto la información producida por los estados financieros puede explicar los rendimientos de las acciones. Este estudio tiene como objetivo analizar la influencia de la política de dividendos y el nivel de gobernabilidad en rendimientos de las acciones anormales de las sociedades cotizadas en la BM \& FBOVESPA. Esta investigación es cuantitativa, con el análisis de 255 empresas, sobre los impactos del aviso de pago de dividendos sobre la rentabilidad anormal de la acción a través de un modelo de regresión lineal múltiple. Los resultados mostraron que los rendimientos anormales experimentaron grandes variaciones y hay una relación directa entre los rendimientos de dividendos y rendimientos de las acciones anormales, contrastando el 
estudio Novis Neto y Saito (2003). Sin embargo, ellos corroboraron Nagem y Amaral (2012), acerca de las rentabilidades anormales sufren grandes variaciones sin una relación directa entre los rendimientos de dividendos y rendimientos de las acciones anormales; el gobierno corporativo variables mostró resultados insignificantes, con la evidencia de que no influye en los rendimientos de las acciones anormales; y las sociedades cotizadas en algunos diferentes niveles de gobierno corporativo de la Ibovespa tiene ningún significado en el poder del informativo de regreso anormal.

Palabras clave: Dividendo de distribución. Anormal Retorno de las Acciones. Informatividad. Gobierno Corporativo.

\section{INTRODUÇÃO}

Os valores comerciais das ações levam em considerações diversas nuances e influências como a expectativa do mercado, políticas econômicas, infraestruturas, nível de confiança, e etc., que combinadas agregam o valor acionário. Dessa premissa, em meados da década de 60 começaram a surgir trabalhos, como por exemplo, Ball e Brown (1968) e Beaver (1968), que analisaram uma associação dos números contábeis com os preços das ações.

Dentro deste contexto, ao se discutir a informação sobre os dividendos, a Teoria da Irrelevância da Política de Dividendos para o preço das ações proposta por Modigliani e Miller (1961) foi um dos primeiros estudos que marcaram este debate. Contrapondo, Gordon (1963) e Lintner (1962) relataram o inverso, construindo a base da Teoria positiva da politica de dividendos. E ainda sobre essa discussão, Brennan (1970) indica uma Teoria que sustenta a influência negativa dos dividendos.

$\mathrm{Na}$ literatura nacional, Novis Neto e Saito (2003) identificaram uma relação direta entre o dividend yield e o retorno anormal acumulado no período pós-pagamento de dividendos. Na mesma linha, Kuronuma et al. (2004) analisaram está mesma relação e corroboraram os resultados de Novis Neto e Saito (2003). No entanto, o estudo de Nagem e Amaral (2013) analisaram o dividendo yield e o retorno anormal acumulado em período de instabilidade econômica de 2009 a 2011, e os achados são opostos aos identificados nos estudos anteriores desenvolvidos por Novis Neto e Saito (2003) e Kuronuma et al. (2004).

Nessa perspectiva diversos estudos, tais como Ball e Brown (1968) e Beaver (1968), começaram a utilizar informações contábeis como parâmetro para as decisões de investimentos nos mercados de capitais, assim, a contabilidade passa a ter uma perspectiva informacional na exploração da relação entre os números contábeis e os preços das ações (WATTS; ZIMMERMAN, 1990).

Ball e Brown (1968) relatam que o lucro líquido é um critério de informação contábil relevante para os investidores como critério na decisão de investir na empresa, deste modo, as informações produzidas pelas demonstrações contábeis podem explicar o retorno das ações. Nesse contexto, diversas outras variáveis contábeis podem influenciar as decisões dos investidores, inclusive os dividendos.

No que tange a questão informatividade dos lucros, pode-se verificar uma interação entre o lucro e outras informações contábeis para verificar se sua capacidade informacional pode ser melhorada. Francis, Schipper e Vicent (2005) constaram no ambiente americano que os dividendos são mais informativos que os lucros contábeis para a informatividade dos preços das ações. No Brasil, Brugni et al. (2012) analisaram se os lucros interagidos com os dividendos apresentam mais capacidade informacional, os resultados apontaram que contribuem positivamente para a informatividade do lucro como variável explicativa do retorno das ações. 
A função informativa da contabilidade somada à aplicação da abordagem positiva nas décadas posteriores permitiu que fossem encontradas evidencias da informatividade com outras variáveis como: tamanho da empresa (FREEMAN, 1987; CHANEY; JETER, 1992; JIAMBALVO, 2002), relação do valor de mercado da firma e o valor contábil do patrimônio líquido (COLLINS; KOTHARI, 1989), nível de endividamento das empresas (DHALIWAL et al., 1991), a adoção de diferentes níveis legais e Governança Corporativa (LA PORTA et al., 1998; BALL; KOTHARI; ROBIN, 2000).

O presente artigo utiliza a metodologia do estudo adaptada de Francis, Schipper e Vicent (2005) e Brugni et al. (2012), com uma perspectiva da governança corporativa. Assim, esta pesquisa busca responder ao seguinte questionamento: Qual a influência dos níveis de governança corporativa e das políticas de dividendos adotadas pelas empresas nos retornos anormais dos preços de suas ações?

Para responder a tal questionamento, o norte deste estudo tem por objetivo analisar a influência das políticas de dividendos e o nível de governança nos retornos anormais das ações das empresas listadas na BM\&FBovespa no período de 2010 a 2013.

Nesta perspectiva, de um lado busca-se analisar a influência das políticas de dividendos, tecendo um paralelo sobre a influência direta das políticas e distribuição de dividendos no retorno anormal das ações (retorno de lucro acima da média de mercado). E por outro lado, analisar a influência dos dividendos em empresas que pertencem a um nível de governança corporativa no retorno anormal das ações das empresas listadas na BMF\&Bovespa.

A discussão inicial surgiu no ambiente americano com a pesquisa desenvolvida por Francis, Schipper e Vicent (2005) que evidenciaram que dividendos são mais informativos que os lucros contábeis para a informatividade dos preços das ações em empresas com duas classes de ações. Brugni et al. (2012) replicaram o estudo no ambiente brasileiro e em sua pesquisa com dados entre 2000 á 2009 verificaram que a interação entre lucro e dividendos era mais informativo para explicar os retornos das ações. Assim, essa pesquisa busca verificar se empresas que distribuem dividendos e pertencem a um nível de governança corporativa tem retornos anormais em suas ações.

Adicionalmente, a presente pesquisa verifica a relação entre os dividendos e o retorno anormal das ações em um período pós-crise de 2010 a 2013. Conforme supracitado Novis Neto e Saito (2003) e Kuronuma et al. (2004) identificaram uma relação direta entre esses fatores. Entretanto, Nagem e Amaral (2013) não evidenciaram tal relação. Como contribuição, o estudo busca expandir a literatura existente e apresentar novos resultados empíricos com a intenção de mitigar os resultados contraditórios.

\section{FUNDAMENTAÇÃO TEÓRICA}

Nesta seção apresentam-se os eixos teóricos com uma revisão de literatura, contemplando as teorias sobre os dividendos, a distribuição de dividendos, a informatividade contábil e as peculiaridades da legislação brasileira no tratamento dos dividendos.

\subsection{DIVIDENDOS E JUROS SOBRE CAPITAL PRÓPRIO NA LEGISLAÇÃO BRASILEIRA}

Ross, Wasterfield e Jaffe (2002) relatam que os pagamentos de dividendos aos acionistas constituem um retorno do capital investido direta ou indiretamente pelos acionistas. Os dividendos é parcela do lucro paga pelas empresas aos acionistas que possuem ações das mesmas. 
A legislação societária brasileira regulamenta que o estatuto da empresa poderá estabelecer o dividendo como porcentagem do lucro ou do capital social, e que na omissão do estatuto o dividendo obrigatório não pode ser inferior a $25 \%$ (vinte e cinco por cento) do lucro líquido ajustado (BRASIL, 1976). As ações preferenciais têm prioridade de na distribuição dos dividendos, fixo ou mínimo; prioridade no reembolso do capital, com prêmio ou sem ele; ou na acumulação das preferências e vantagens (BRASIL, 1976).

A política de dividendos no Brasil é diferenciada comparada a outros países desenvolvidos como Estados Unidos e Inglaterra. Particularidades brasileiras, tais como: obrigatoriedade no pagamento de dividendos, aspectos de contabilização de operações e tributação sobre este tipo de rendimento são exemplos de diferenças (ROSS, WESTERFIELD; JAFFE, 2002; BRUGNI et al., 2012).

A legislação societária brasileira ainda determina que a remuneração dos acionistas pode ser efetuada de duas formas: dividendos ou juros sobre capital próprio (BRASIL, 1995; SARLO NETO, 2009). Os dividendos e juros sobre capital próprio diferem entre principalmente quanto à base de cálculo e definição. Os juros sobre capital próprio são uma remuneração capital próprio dos acionistas com base de cálculo do patrimônio líquido; e os dividendos são os lucros distribuídos aos acionistas apurados a partir do próprio lucro líquido (SARLO NETO, 2009).

Rolim (1996) destaca que a remuneração pelos juros sobre capital próprio trata-se de um incentivo no autofinanciamento das empresas, reduzindo diferenças entre financiamento de terceiros e próprio.

A criação dos juros sobre capital próprio foi destinada a minimizar os efeitos da extinção da correção monetária, diminuindo a carga tributária nas empresas (CARVALHO, 2003; SARLO NETO, 2009). A contabilização dos juros deve ser como despesa financeira na demonstração do resultado do exercício, e a Comissão dos valores mobiliários (CVM) regulamenta que devem ser estornados para fins de cálculo do lucro líquido (SARLO NETO, 2009).

Pressi (2003) retrata a natureza jurídica do JSCP em duas vertentes: primeiro, a imputação do JSCP como despesa financeira (pessoa jurídica) e rendimento financeiro (beneficiário); segundo, que não passa de uma maneira de distribuição de resultados. $\mathrm{O}$ cálculo do JSCP podem ser a taxa que a empresa considerar adequada (CARVALHO, 2003).

Destaca-se que a legislação societária determina a faculdade de imputação dos JSCP aos dividendos. Desta maneira, os JSCP podem ser incorporados nos valores do dividendo mínimo obrigatório (CARVALHO, 2003; SARLO NETO, 2009). Desta forma esta pesquisa busca anular o efeito dos juros sobre capital incorporados nos dividendos para análise dos reflexos nos retornos anormais das ações pós-pagamentos dos dividendos. E posterior verificar a informatividade do lucro interagidos com os dividendos.

\subsection{POLÍTICAS E TEORIA DOS DIVIDENDOS}

A discussão sobre o impacto da política e distribuição dos dividendos no valor das empresas é um assunto que tem grandes controvérsias. Diante das pesquisas existentes, uma aponta para a irrelevância da política de dividendos (MODIGLIANI; MILLER, 1961), outras sustentam-se na relevância positiva dos dividendos (GORDON, 1963; LINTNER, 1962), e também há relevância negativa dos dividendos (BRENNAN, 1970), dentre outras. A complicação de solucionar está problemática é devido à complexidade de fatores que interferem no processo de avaliação das empresas e de decisões de financiamento (NAGEM; AMARAL, 2013).

Modigliani e Miller (1961) propõem a Teoria da Irrelevância dos Dividendos. Os autores investigaram o impacto da política de dividendos no preço das ações na avaliação de 
uma empresa. A pesquisa detectou que uma irrelevância dos dividendos devido ao efeito duplo no preço das ações. O dividendo tem um impacto positivo ao aumentar o fluxo de caixa dos acionistas atuais, por outro lado, este impacto é anulado devido aporte para pagamento dos dividendos ocasionarem futuramente a necessidade de emitir novas ações para financiamento da empresa (MODIGLIANI; MILLER, 1961).

A pesquisa de Modigliani e Miller (1961) sustenta-se que não existe uma estrutura financeira ótima entre capital próprio e de terceiros que impacte positivamente no valor das ações. E que o estudo é respaldado na teoria na hipótese de mercado perfeito, a racionalidade dos agentes do mercado e que não existe custos de transação (LOSS; SARLO NETO, 2003; KURONUMA et al., 2004).

Ross, Westerfield e Jaffe (2002), destacam que a ideia da teoria da irrelevância da política de dividendos proposta por Modigliani e Miller refere-se ao aspecto que os investidores podem criar uma política de dividendos por si só, onde em uma posição insatisfeita pode desfazer a política de dividendos da empresa reinvestindo dividendos ou vendendo ações.

Contrapondo Modigliani e Miller (1961), Gordon (1963) e Lintner (1962) defendem a Teoria da influência positiva de dividendos (Teoria do Pássaro na Mão). Esta teoria baseia-se no ponto central de que é melhor assegurar um valor presente do que aguardar por mais no futuro. Segundo Kuronuma et al. (2004) a teoria da influência positiva sugere que há uma relação direta entre a política de dividendos da empresa e seu valor de mercado.

Lintner (1956) afirma que os investidores preferem retornos advindos dos dividendos aos originados de ganho de capital, devido ao risco e estabilidade relacionados. Em vista disso, a teoria também é conhecida como Teoria do "Pássaro na Mão".

Segundo Nagem e Amaral (2013), os estudos de Gordon e Lintner supõem que o preço de uma ação não é sobre as expectativas de retorno da empresa, e sim, devido à expectativa de pagamento de dividendos futuros a valor presente.

Já a Teoria da influência negativa dos dividendos na avaliação do valor das empresas é sustentada incialmente por Brennan (1970). O autor apresenta a partir de um modelo econométrico os efeitos dos impostos e da valorização da empresa sobre a política financeira da empresa. Brennan (1970) inclui no modelo de precificação de ativos financeiros (CAPM) uma taxa de rendimento dos dividendos em relação ao preço das ações, se a taxa de dividend yelds de determinada ação é alta, logo esta deve ser considerada no cálculo do retorno do ativo. Deste modo, no caso de dividendos altos é necessário um retorno maior para ações com a finalidade de compensar a desvantagem fiscal no ambiente americano para os investidores.

Loss e Sarlo Neto (2003) complementam com a teoria da preferência tributária, uma vez que se tem taxação de impostos de forma diferenciada sobre ganhos de capital e de dividendos, os acionistas tenderão a escolher a que tiver menor encargo tributário.

\subsection{A TEORIA POSITIVA E A INFORMATIVIDADE DOS LUCROS CONTÁBEIS}

No debate sobre informatividade contábil, faz necessário relacionar ao surgimento da abordagem positiva. Antigamente as pesquisas em contabilidade tinha caráter mais normativo, atualmente as pesquisas são em sua grande maioria positiva. Segundo Lopes e Iudicibus (2012) a pesquisa positiva tem a intenção de explicar e predizer o que acontece na realidade das empresas, e a pesquisa normativa busca prescrever a melhor forma de mensuração de operações contábeis.

De acordo com Watts e Zimmerman (1990) a teoria positiva da Contabilidade surgiu dos estudos de Ball e Brown (1968) e Beaver (1968), como uma forma de integrar à metodologia empírica de finanças com temas referentes à relação de mercados de capitais e 
contabilidade. Em outras palavras, a teoria positiva vista como uma forma de incorporar as teorias baseadas na economia explicando a relação entre contabilidade e mercados de capitais.

A contabilidade passou para a Information Approach, em que a pesquisa em contábil busca verificar a utilidade e a influência das demonstrações contábeis sobre as ações de seus usuários (SARLO NETO et al., 2003; SARLO NETO, 2009).

Ball e Brown (1968) com o objetivo de verificar se a divulgação dos lucros anuais retratava os fatores que impactavam nos preços das ações, os autores analisaram a influência dos lucros residuais nos preços das ações negociadas na Bolsa de Nova York. O estudo de Ball e Brown (1968) forneceram evidências da utilização e da relevância das informações contábeis para os usuários participantes do mercado acionário (SARLO et al., 2003).

O Lucro líquido é uma informação contábil relevante para os investidores como critério na decisão de investir na empresa e explicar o retorno das ações (BALL; BROWN, 1968). No entanto ressalta-se que outras variáveis contábeis podem influenciar as decisões dos investidores, inclusive os dividendos. Uma interação entre o lucro e outras informações contábeis pode melhorar a capacidade informacional (BRUGNI et al. 2012).

Sarlo Neto, Galdi e Dalmacio (2009) afirmam que vários estudos constaram que a divulgação dos lucros contábeis afeta os preços das ações, no entanto os achados não seguem uma correlação perfeita. Devido a isso, tornam-se necessárias novas pesquisas explorando a relação entre lucros e preços (SARLO NETO; GALDI E DALMACIO, 2009). Além devido às características particulares do mercado acionário brasileiro: volatilidade do mercado, presença marcante do estado, excessiva regulamentação da contabilidade, mercado acionário concentrado, fraca proteção dos acionistas (SARLO NETO, 2004).

\section{METODOLOGIA DA PESQUISA}

Com a finalidade de atingir o objetivo de analisar a influência das políticas de dividendos e o nível de governança nos retornos anormais das ações das empresas listadas na BM\&FBovespa no período de 2010 a 2013. Numa primeira fase utiliza-se um estudo de evento para analisar o impacto do pós-anuncio dos dividendos no retorno anormal da ação. Segundo Campbell, Lo \& MacKinlay (1997), em virtude da racionalidade do mercado, os efeitos de um evento são imediatamente refletidos nos preços das ações.

Dado a disparidade dos resultados entre a relação de dividendos e retorno anormal das ações, apresentados por Novis Neto e Saito (2003) e Kuronuma et al. (2004) e Nagem e Amaral (2013), surge a primeira hipótese a ser testada na pesquisa:

$\mathbf{H}_{0 \mathbf{a}}=$ Há uma relação direta entre o dividend yield e o retorno anormal acumulado destas ações no período pós-pagamento de dividendos.

Hipótese baseada primordialmente em Novis Neto e Saito (2003). No entanto, para fins desse estudo será considerada a composição dos dividendos fazendo a distinção entre o que corresponde a juros sobre capital próprio e o pagamento efetivo de dividendos no final do período. Importante destacar que está pesquisa situa-se num período pos-crise.

Em segundo momento, o estudo busca analisar a influência dos dividendos na melhoria da informativade dos lucros. Na década de 60 deu-se origem a teoria contábil positiva por meio do estudo Ball e Brown (1968), Beaver (1968), dentre outros, que buscaram analisar a relação entre variáveis contábeis e de mercado. Segundo Lopes e Iudicibus (2012) teoria positiva refere-se aquela que busca explicar e predizer determinados fenômenos com base no que acontece na realidade.

Por conseguinte, a segunda hipótese nula surge da seguinte maneira:

Hob: Empresas listadas em alguns níveis diferenciados de governança corporativa tem influência no poder de informatividade do lucro do retorno anormal das ações por meio das variáveis de lucro ou dividendos. 
A partir de um modelo de regressão linear múltipla busca explicar a informatividade dos lucros contábeis pode ser influenciada pela governança corporativa das empresas.

A população deste artigo são as empresas que possuem ações em negociação na BM\&BOVESPA. A pesquisa abrange os anos de 2010 á 2013. A base de dados utilizada nesta pesquisa foi obtida por meio de informações coletadas na base de dados do software Economática®.

A amostra foi composta pelos eventos em que houve pagamento de dividendos das ações de empresas não financeiras negociadas na Bolsa de Valores de São Paulo no ano de 2013.

O evento estudado é o anúncio do pagamento dos dividendos, o impacto no retorno anormal da ação. A data do evento "EX-1": dia anterior à data ex-dividendo.

Segue fórmula do Retorno da ação:

$$
\mathrm{R}_{i t}=\frac{P_{t}+D_{t}}{P_{t-1}}-1
$$

Em que:

$\mathrm{R}_{\mathrm{it}:}$ retorno real do ativo i na data $\mathrm{t}$;

$\mathrm{P}_{\mathrm{t}}$ : Preço diário do fechamento da Ação na data t;

Dt: dividendos ou juros sobre capital por ação em $t$.

Os retornos normais foram calculados por meio do modelo estatístico de fator único que propõe uma relação linear entre o retorno da ação e o retorno da carteira de mercado (MacKinlay, 1997).

$$
E\left(R_{i t}\right)=\alpha+\beta_{I} R_{m t}
$$

Em que:

$E\left(R_{i t}\right):$ Retorno esperado da ação i;

$\mathrm{R}_{\mathrm{mt}}$ : Retorno do índice IBOVESPA na data $\mathrm{t}$;

A proxy da carteira de mercado foi o Ibovespa para o modelo de fator único proposto acima. Procedeu-se com a apuração do retorno anormal para cada ação utilizando a seguinte fórmula:

Em que:

$$
A R_{i t}=R_{i t}-E\left(R_{i t}\right)
$$

ARi: Retorno Anormal de cada ação i;

$\mathrm{R}_{\mathrm{ei}}$ : Retorno normal ou retorno real i;

$E\left(R_{i t}\right)$ : Retorno esperado de cada ação i.

Na sequência, calcularam-se os retornos anormais acumulados diários para cada ação.

$$
C A R_{i t}=\sum_{t=1}^{T} E\left(R_{i t}\right)
$$

Por fim, apurou-se o dividend yield de cada evento:

$$
D Y=\frac{D}{P_{E x-1}}
$$

D: dividendo pago por ação

$\mathrm{P}_{\mathrm{EX}-1}$ : preço da ação na data EX-1 
O procedimento de teste utilizado foi à estatística T-student para diferença de médias. Por meio do teste de Fischer. Diferentemente de Nagem (2012) que refutou a relação direta entre dividend yields e retorno anormal da ação, dividiu-se a amostra em três grupos de acordo com o nível de dividend yields: altos, intermediários e baixos. E exclui dos dividendos os juros sobre próprio pago mensalmente ou trimestralmente.

Utilizou-se um modelo de regressão múltipla linear para testar a hipótese formulada da informatividade dos lucros interagida com os dividendos, desenvolvido por Brugni et al. (2012), incluindo no modelo a dummy de governança corporativa.

$$
\begin{aligned}
R A_{i, t}=\alpha_{0}+ & \beta_{1} L L A_{i, t}+\beta_{2} D I V A_{i, t}+\gamma_{1} L L A_{i, t} \cdot D I V A_{i, t}+\omega_{1} T A M_{i, t}+\omega_{2} E N D_{i, t} \\
& +D N D G+\varepsilon_{i, t}
\end{aligned}
$$

Em que: $R A_{i_{a} t}=$ Retorno Anormal da ação da empresa i no período $\mathrm{t} ; \alpha_{0}=$ Intercepto; $\beta_{1}=$ Coeficiente angular entre o Lucro Líquido Ajustado e o Retorno Ajustado; $L L A_{i, t}=$ Lucro Líquido Ajustado da empresa $\mathrm{i}$ no período $\mathrm{t} ; \beta_{2}=$ Coeficiente angular entre o Dividendo Ajustado e o Retorno Ajustado; $D I V A_{i, t}=$ Dividendo ajustado da empresa i no período $\mathrm{t} ; \gamma_{1}=$ Coeficiente angular entre a interação do LLA e DIVA e o Retorno Ajustado; $L L A_{i, t}$. $D I V A_{i, t}=$ Interação entre o Lucro Líquido Ajustado e o Dividendo Ajustado; $\omega_{1}=$ Coeficiente angular entre a variável Tamanho e o Retorno Ajustado; $T A M_{i, t}=$ Variável de controle do Tamanho da empresa i no período $t ; \omega_{2}=$ Coeficiente angular entre a variável Endividamento e o Retorno Ajustado; $E N D_{i, t}=$ Variável de controle do endividamento da empresa i no período t; DNGC = Variável Dummy que assume valor de 1 para empresas listadas em algum dos níveis diferenciados de Governança Corporativa do Bovespa; $\varepsilon_{i, t}=$ Termo de erro do Modelo.

O modelo apresenta como variável dependente o retorno anormal do preço das ações. O retorno anormal da ação dado pela fórmula com base em pesquisa de Sarlo Neto (2009) e Francis, Schipper e Vincent (2005) e Brugni et al. (2012) e considerou-se:

$$
\mathrm{RA} i=R_{i t}-\mathrm{RIBOV}_{t}
$$

Em que:

RA $i=$ Retorno Anormal da ação da empresa i no período t;

$R_{i t}=$ Retorno da ação da empresa i no período t;

RIBOV $_{t}=$ Retorno do mercado no período t (retorno do mercado a variação do IBOVESPA);

A apuração do retorno da ação e do retorno do mercado (RIBOV) foram calculados similarmente, de acordo com equação 8 e 9 abaixo:

$$
\mathrm{R}_{i t}=\frac{P_{i t}+P_{i, t-1}}{P_{i, t-1}} \quad \text { (8) } \quad \text { e } \quad \text { RIBOV }_{t}=\frac{I B O V_{i t}+I B O V_{t-1}}{I B O V_{t-1}}
$$

Quanto as variáveis independentes: LLA trata-se do lucro líquido divulgado ajustado pelo valor de mercado; DIVA é representada pelo total de dividendos divulgados no exercício, ajustados pelo valor de mercado da empresa. Utilizou-se duas variáveis de controle tamanho e endividamento. A proxy do tamanho da empresa foi utilizada o logaritmo natural do ativo total da empresa, já o endividamento foi representado pela relação entre o capital de terceiros (passivos operacionais e não operacionais, de curto e longo prazo) e o Passivo Total (BRUGNI et al., 2012). 


\section{DESCRIÇÃO E ANÁLISE DOS RESULTADOS}

\subsection{DIVIDEND YIELDS E O RETORNO ANORMAL DAS AÇÕES}

A primeira hipótese da pesquisa busca testar se há relação entre os dividend yields e o retorno anormal das ações. Para está estudo excluíram os juros sobre capital próprio pagos mensalmente ou trimestralmente. E dividiu-se os dividend yields em altos, intermediários e baixos para explicar a relação com o retorno anormal das ações. Abaixo segue a Figura 1:

Figura 1 - Relação entre Retornos Anormais e Dividend Yields

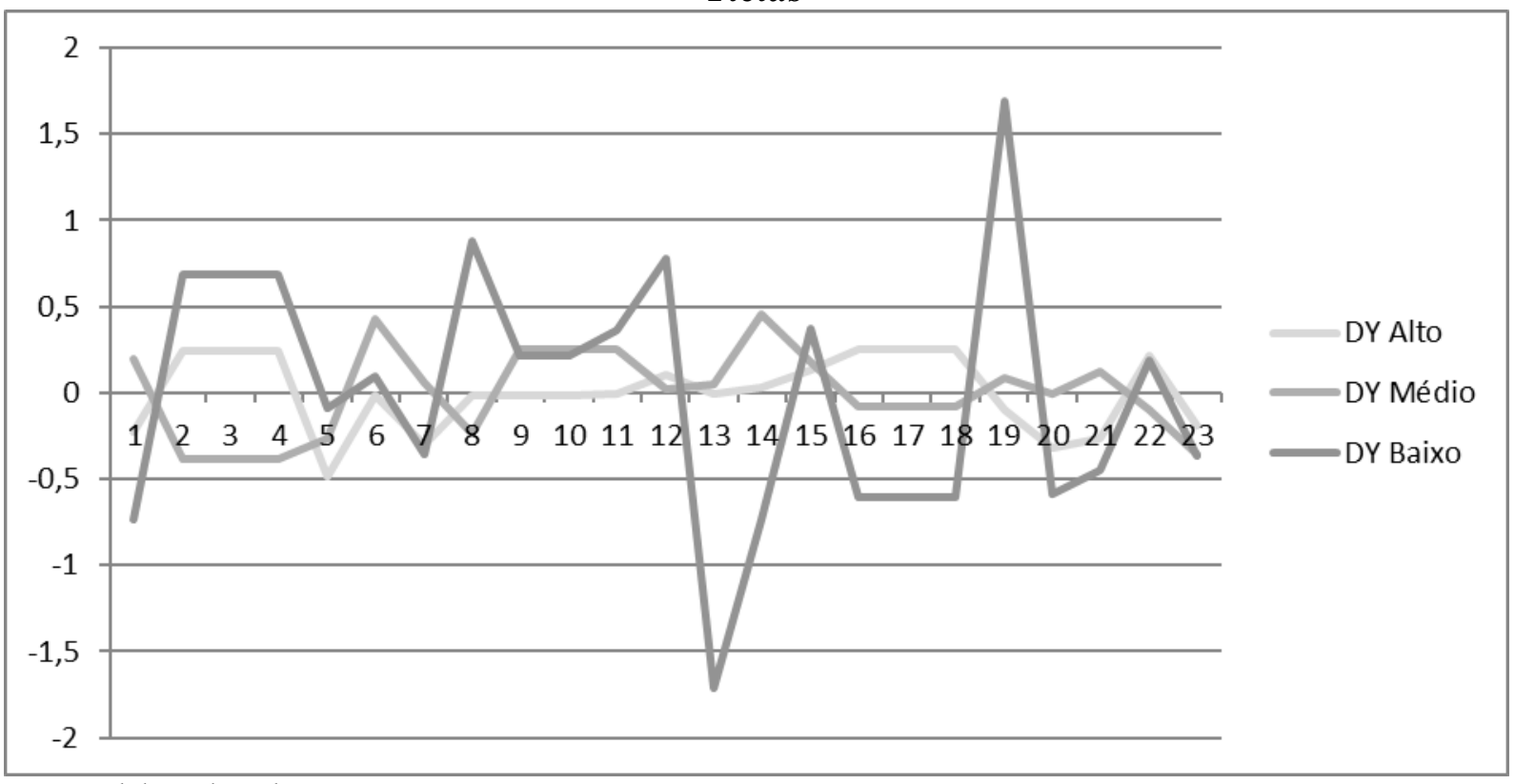

Fonte: Elaborada pelos autores.

Observa-se pela Figura 1 que têm oscilações nos dividend yield. Os resultados contrapõem Novis Neto e Saito (2003) que identificaram uma relação direta entre o dividend yield e o retorno anormal acumulado no período pós-pagamento de dividendos. Este achado corrobora com os resultados de Nagem e Amaral (2012), em que os retornos anormais sofreram grandes variações e não é possível afirmar que existe uma relação direta entre dividend yields e retorno anormal das ações.

Dessa forma, não se pode afirmar que há a uma relação direta entre o dividend yield e o retorno anormal acumulado destas ações no período pós-pagamento de dividendos, não se aceita $\mathrm{H}_{0 \mathrm{a}}$.

\subsection{INFORMATIVIDADE DOS LUCROS: INTERAÇÃO COM DIVIDENDOS E GOVERNANÇA CORPORATIVA}

A Segunda hipótese retrata Empresas listadas em alguns níveis diferenciados de governança corporativa do tem influência no poder de informatividade do lucro do retorno anormal das ações por meio das variáveis de lucro ou dividendos. 
Revista Ambiente Contábil - ISSN 2176-9036 - UFRN - Natal-RN. v. 8. n. 2, p. 233 - 248, jul./dez. 2016.

Tabela 1 - Estatística Descritiva

\begin{tabular}{c|c|c|c|c|c}
\hline Variável & Obs & Média & Desvio Padrão & Mínimo & Máximo \\
\hline RA & 246 & 0.436176 & 18.41093 & -52.8443 & 103.3083 \\
\hline LLA & 246 & -0.36772 & 1.988585 & -22.4488 & 0.799801 \\
\hline DIVA & 246 & 0.03335 & 0.0562627 & 0 & 0.464582 \\
\hline LLADIVA & 246 & 0.000237 & 0.0302748 & -0.32386 & 0.054944 \\
\hline TAM & 246 & 6.722213 & 0.8314178 & 3.775974 & 9.11525 \\
\hline ENDV & 246 & 0.998532 & 4.494005 & 0.005381 & 70.368 \\
\hline DNDG & 246 & 0.711382 & 0.4540436 & 0 & 1 \\
\hline
\end{tabular}

Fonte: Elaborada pelos autores.

Nota-se na Tabela 1, que com os resultados, a estatística descritiva apresentou o maior valor de desvio padrão, respectivamente para: a variável dependente, retorno anormal das ações (RA); o endividamento (ENDV) é variável de controle; e o lucro líquido ajustado (LLA). Segue Tabela 2 com os coeficientes de Correlação de Pearson.

Tabela 2 - Coeficientes de Correlação de Pearson.

\begin{tabular}{c|c|c|c|c|c|c}
\hline & RA & LLA & DIVA & LLADIVA & TAM & ENDV \\
\hline LLA & 0.255 & & & & & \\
\hline DIVA & 0.1573 & 0.1122 & & & & \\
\hline LLADIVA & 0.0511 & 0.0405 & -0.5288 & & & \\
\hline ÍTAM & 0.0259 & 0.166 & 0.3031 & -0.0951 & & \\
\hline ENDV & -0.0027 & -0.2396 & -0.0527 & 0.0009 & -0.2575 & \\
\hline DNDG & 0.0182 & 0.0157 & 0.0796 & -0.0505 & 0.2672 & -0.1317 \\
\hline
\end{tabular}

Fonte: Elaborada pelos autores.

Com os resultados da correlação de Pearson pode-se afirmar que nenhuma das variáveis apresentara correlação forte. E que a correlação fornece evidências iniciais de que existe um grau de associação positiva entre as variáveis independentes e a variável dependente.

Tabela 3 - Resultados da Regressão com Governança

\begin{tabular}{c|c|c}
\hline RA & Coeficiente & Erro Padrão \\
\hline LLA & $2.895195^{*}$ & 0.5808565 \\
\hline DIVA & $102.6204^{*}$ & 24.40777 \\
\hline LLADIVA & $139.0593^{*}$ & 43.379 \\
\hline TAM & -0.2944448 & 0.491355 \\
\hline ENDV & -0.2625269 & 2.532467 \\
\hline DNDG & 0.1952235 & 9.703909 \\
\hline Constante & -1.981202 & \\
\hline Número de Obs & & \\
\hline Prob $>$ F & 246 & \\
\hline $\mathrm{R}^{2}$ & 0.0000 & \\
\hline $\mathrm{R}^{2}$ Ajustado & 0.1407 & \\
\hline
\end{tabular}

Fonte: Elaborada pelos autores. 
Por meio da Tabela 3, infere-se que o modelo é significativo e as variáveis, lucro líquido ajustado (LLA); Dividendos Ajustados (DIVA) e a interação entre o lucro e o dividendo ajustado (LLADIVA) são significativos a 1\%. E constata-se que o coeficiente da variável LLADIVA tem a maior relação de informatividade sobre o retorno anormal. Outro achado é a variável dummy de governança corporativa (DNDG) apresentou resultado insignificante, com evidências que a Governança Corporativa não influência no retorno anormal das ações, e as demais variáveis do modelo também são insignificantes. Abaixo Tabela 4.

Tabela 4 - Resultados da Regressão com interações com Governança Corporativa

\begin{tabular}{l|r|r}
\hline RA & Coeficiente & Erro Padrão \\
\hline LLA & -2.70112 & 1.487846 \\
\hline DIVA & 8.78976 & 62.14925 \\
\hline LLADIVA & $160.6383^{*}$ & 45.24928 \\
\hline TAM & -0.0032253 & 1.50629 \\
\hline ENDV & -0.2791496 & 0.2864192 \\
\hline DNDG & -3.074619 & 3.270441 \\
\hline DNDGDIVA & 110.8772 & 67.53607 \\
\hline DNDGLLA & -0.2220424 & 1.601416 \\
\hline Constante & -1.310695 & 9.799361 \\
\hline Number of obs & 246 & \\
\hline Prob > F & 0 & \\
\hline R-squared & 0.1505 & \\
\hline Adj R-squared & 0.1218 & \\
\hline Fo E & & \\
\hline
\end{tabular}

Fonte: Elaborada pelos autores.

Nesse modelo foi interagida a variável dummy de governança (DNDG) com as variáveis de lucro líquido ajustado (LLA) e (DIVA). Constatou-se que as variáveis interagidas governança e dividendos (DNDGDIVA) e governança e lucro líquido ajustado (DNDGLLA) são insignificantes para o modelo. Dessa forma este estudo contribui para a literatura com a sinalização de que empresas listadas em alguns níveis diferenciados de governança corporativa do Ibovespa não tem significância no poder de informatividade do retorno anormal através das variáveis LLA e DIVA.

Por fim, não se pode afirmar que empresas listadas em níveis diferenciados de governança corporativa têm influência no poder de informatividade do lucro no retorno anormal das ações por meio das variáveis de lucro ou dividendos, rejeita-se $\mathrm{H}_{0 \mathrm{~b}}$. Adicionalmente, conforme tópico anterior verificou-se não se pode afirmar que há a uma relação direta entre o dividend yield e o retorno anormal acumulado destas ações no período pós-pagamento de dividendos, rejeita-se $\mathrm{H}_{0 \mathrm{a}}$.

\section{CONSIDERAÇÕES FINAIS E SUGESTÕES DE PESQUISAS FUTURAS}

Este estudo tem por objetivo analisar a influência das políticas de dividendos e o nível de governança nos retornos anormais das ações das empresas listadas na BM\&FBovespa no período de 2010 a 2013.

A pesquisa inicialmente faz um estudo de eventos analisando os reflexos do pagamento de dividendos no retorno anormal das ações. Os resultados contrapõem Novis 
Neto e Saito (2003) que identificaram uma relação direta entre o dividend yield e o retorno anormal acumulado no período pós-pagamento de dividendos. Este achado corrobora os de Nagem e Amaral (2012), em que os retornos anormais sofreram grandes variações e não foi possível afirmar a existência de uma relação direta entre dividend yields e retorno anormal das ações. Outras relações poderiam ser testadas para buscar relações entre a informatividade contábil sob a ótica não apenas da política e distribuição dos dividendos e segmentos de governança, mas envolvendo outras variáveis como: tamanho da empresa (FREEMAN, 1987; CHANEY; JETER, 1992; JIAMBALVO, 2002), porém, numa perspectiva de um mercado atual e considerando a rapidez com que o mercado recebe as informações; relação do valor de mercado da firma e o valor contábil do patrimônio líquido (COLLINS; KOTHARI, 1989); nível de endividamento das empresas (DHALIWAL et al., 1991); a adoção de diferentes níveis legais e Governança Corporativa (LA PORTA et al., 1998; BALL; KOTHARI; ROBIN, 2000).

Em segundo momento, a partir de um modelo de regressão linear múltipla busca explicar a informatividade dos lucros contábeis nos retornos anormais das ações que podem ser influenciados pela governança corporativa das empresas.

No contexto brasileiro, pode-se citar também a pesquisa de Gonçalves, Rodrigues e Macedo (2013) que avaliaram a capacidade explicativa especificamente do lucro líquido e do patrimônio líquido em IFRS e BR-GAAP. Como resultados identificaram maior relevância em ambiente IFRS, sendo que neste ambiente o Lucro Líquido teve seu poder de explicação reduzido. Já os autores Ramos e Lustosa (2013) investigaram se a adequação das normas contábeis vigentes no Brasil às normas internacionais acrescentou relevância para explicar o preço das ações. Os resultados corroboram a afirmação de um aumento na relevância da informação contábil após a convergência às normas internacionais. Percebe-se que a informatividade dos lucros pode ser influenciada por diversas variáveis e que de alguma forma trará reflexos para o preço das ações.

Por fim, os achados apontaram ainda que a governança corporativa apresentou resultado insignificante, com evidências que a Governança Corporativa apenas, não influência no retorno anormal das ações, e as demais variáveis do modelo também são insignificantes. $\mathrm{E}$ que a interação com os lucros e dividendos diminuem a informatividade nos retornos anormais das ações.

\section{REFERÊNCIAS}

BALL, R.; BROWN, P. An empirical evaluation of accounting income numbers. Journal of Accounting Research, v. 6, p. 159-178, 1968.

BALL, R.; KOTHARI, S.; ROBIN. A. The Effect of International Institutional Factors on Properties of Accounting Earnings, Journal of Accounting and Economics 29, p. 1-51, 2000.

BEAVER, W. The information content of annual earnings announcements. Journal of Accounting Ressearch, Supplement, p. 62-92, 1968.

BRASIL. Congresso Nacional. Lei nº 6.404/1976. Diário Oficial [da] República Federativa do Brasil. Brasília-DF. Disponível em: <http://www.planalto.gov.br/ccivil_03/leis/16404compilada.htm>. Acesso em: 03 jan. 2015. 
. Congresso Nacional. Lei nº 6.404/1976. Diário Oficial [da] República Federativa

do Brasil. Brasília-DF. Disponível <http://www.planalto.gov.br/ccivil_03/leis/19249.htm>. Acesso em: 03 jan. 2015.

BRENNAN, M. Taxes, market valuation and financial policy. National Tax Journal, v.23, p.417-429, dec. 1970.

BRUGNI, Talles Vianna; SARLO NETO, Alfredo; BASTIANELLO, Ricardo Furieri; PARIS, Patrícia Krauss Serrano. "Influência De Dividendos Sobre a Informatividade Dos Lucros: Evidências Empíricas na BM\&FBOVESPA." Revista Universo Contábil, v. 8, n. 3, p. 82-99, jul./set., 2012.

CAMPBELL, John Y., LO, Andrew W., \& MACKINLAY, A. Craig. "The Econometrics of Financial Markets", Cap. 4. Princeton University Press, 1997.

CARVAlho, E. R. A. Política De Dividendos E Juros Sobre O Capital Próprio: Um Modelo Com Informação Assimétrica. Dissertação (Mestrado, Administração de Empresas) - FGV/Escola de Administração de Empresas de São Paulo, São Paulo, 2003.

CHANEY, P. K.; JETER, D. C. The Effect of Size on the Magnitude of Long-Window Earnings Response Coefficients. Contemporary Accounting Research, vol. 8, 540-560, 1992.

COLLINS, D.; KOTHARI, S. An Analysis of the Cross-sectional and Intertemporal Determinants of Earnings Response Coefficients. Journal of Accounting and Economics, vol. 11, 143-181, 1989.

DHALIWAL, D. S.; LEE, K. J.; FARGHER, N. L. The Association between unexpected earnings and abnormal security returns in the presence of financial leverage. Contemporary Accounting Research, v. 8, p. 20-41, 1991.

FRANCIS, J.; SCHIPPER, K.; VICENT, L. Earnings and dividend informativeness when cash flow rights are separated from voting rights. Journal of Accounting and economics, v.39, p.329-360, 2005.

FREEMAN, R. N. The Association Between Accounting Earnings and Security Returns for Large and Small Firms. Journal of Accounting and Economics, vol 9, issue 2, p. 195-228, 1987.

GONÇALVES, J. C.; RODRIGUES, A.; MACEDO, M. A. S. Poder Explicativo de Variáveis Contábeis no Preço das Ações das Companhias Elétricas em Ambiente de IFRS. Revista Ambiente Contábil, v.6, n.1, p. 219-235, 2014.

GORDON, M. J. Optimal investment and financing policy. Journal of Finance, v.28, n.2, p.264-272, may. 1963.

MODIGliani, F.; MiLleR, M.H. Dividend Policy, Growth, and the Valuation. The Journal of Business, v.34, n.4, p.411-433, oct. 1961. 
NAGEM, Lilian Marques; AMARAL, Hudson Fernandes. Retornos Anormais das Ações Pós-Pagamento de Dividendos: Um Estudo Empírico no Mercado Brasileiro a partir de 2009 Revista de Contabilidade e Controladoria. Curitiba, v.5, n.2, p.61-73, maio/ago. 2013.

NOVIS NETO, J. A.; SAITO, R. Pagamentos de dividendos e persistência de retornos anormais das ações: evidência do mercado brasileiro. Revista de Administração da USP, São Paulo, v.38, n.2, p.135-143, abr./jun. 2003.

KURONUMA, A.M.; LUCCHESI, E.P.; FAMÁ, R. Retornos Anormais Acumulados das Ações no Período Pós-Pagamento de Dividendos: Um Estudo Empírico no Mercado Brasileiro. In: Congresso USP de Controladoria e Contabilidade, 4, 2004, São Paulo. Anais... São Paulo: 2004.

LA PORTA, R.; LOPEZ-DE-SILANES, F.; SHEIFER, A.; VISHNY, R. W. Law and Finance. The Journal of Political Economy, v. 106, i. 6, p;. 1113-1155, 1998.

LINTNER, J. Distribution of incomes of corporations among dividends, retained earnings, and taxes. American Economic Review, v.46, n.2, p.97-113, May 1956.

LINTNER, J. Dividends, earnings, leverage, stock prices and the supply of capital to corporations. Review of Economics and Statistics, v.44, p.243-269, aug. 1962.

LOSS, Lenita; SARLO NETO, Alfredo. Política de dividendos, na prática, é importante? Revista de Contabilidade e Finanças, USP - São Paulo. Edição comemorativa, p. 39-53, out. 2003.

LOPES, A. B.; IUDICIBUS, S. Teoria Avançada da Contabilidade. 2. ed.. São Paulo: Atlas, 2012.

JIAMBALVO, J. Contabilidade Gerencial. Rio de Janeiro: LTC, 2002.

MACKINLAY, A.C. Event studies in economics and finance. Journal of Economic Literature, Nashville, v.35, n.1, p.13-39, mar. 1997.

PRESSI, Guilherme. Modelo para avaliação do impacto dos juros sobre o capital próprio na estrutura de capital e no fluxo de caixa das empresas. Rio Grande do Sul, 2003. Dissertação (Mestrado em economia) - Universidade Federal do Rio Grande do Sul - UFRS.

RAMOS, D. A.; LURTOSA, P. R. B. Verificação Empírica da Value Relevance na Adoção das Normas Internacionais de Contabilidade para o Mercado de Capitais Brasileiro. Contexto, v. 13, n. 25 , p. $70-83,2013$.

ROLIM, João Dácio. Remuneração do capital próprio das pessoas jurídicas - aspectos fiscais. In: ROCHA, Valdir de Oliveira. Imposto de Renda: Alterações fundamentais. São Paulo: Dialética, 1996.

ROSS S. A.; WESTERFIELD, R. W.; JAFFE, J. Administração Financeira - Corporate Finance. 2 ed. São Paulo: Atlas, 2002. 
SARLO NETO, A. Relação entre estrutura de propriedade e a informatividade dos lucros no mercado brasileiro. Tese (Doutorado em Contabilidade e Controladoria) Universidade de São Paulo - USP, São Paulo, 2009.

SARLO NETO, A. A relação dos preços das ações à divulgação dos resultados contábeis: evidências empíricas sobre a capacidade a capacidade informacional da contabilidade no mercado acionário brasileiro. Dissertação (Mestrado em Contabilidade) - Instituto Capixaba de Pesquisas em Contabilidade, Economia e Finanças - FUCAPE, Vitória, 2004.

SARLO NETO, A.; LOSS, L.; NOSSA, V.; TEIXEIRA, A. J. C. Uma Investigação sobre a capacidade informacional dos lucros contábeis no mercado acionário brasileiro. In: CONGRESSO USP DE CONTROLADORIA E CONTABILIDADE, Anais... São Paulo, 2003 .

SARLO NETO, A.; GALDI, F. C.; DALMACIO, F. Z. Uma pesquisa sobre o perfil das ações brasileiras que reagem à publicação dos resultados contábeis. Revista Contabilidade e Organizações, v. 3, n. 6, p. 22-40, 2009.

SOARES Jr., Leonildo. Modelo para avaliação do impacto dos juros sobre o capital próprio na estrutura de capital e no fluxo de caixa das empresas. Florianópolis, 2001. Dissertação (Mestrado em Engenharia de Produção), Programa de Pós-Graduação em Engenharia de Produção da Universidade Federal de Santa Catarina.

WATTS, Ross L.; ZIMMERMAN, Jerold L. Positive accounting theory: a ten year perspective. The Accounting Review. v. 65, n.1, p. 131-156, January, 1990. 